\title{
Problems and Challenges to the Modern Bulgarian Family with Children
}

\author{
Todorka Kineva \\ Department of Economic Sociology, University of National and World Economy, Bulgaria
}

\section{Проблеми и предизвикателства пред съвременното българско семейство с деца}

\author{
Тодорка Кинева \\ Катедра „Икономическа социология”, Университет за национално и световно \\ стопанство, България
}

\section{Author Note}

Todorka Kineva https://orcid.org/0000-0002-2108-048X

The author has no conflict of interest to disclose.

Correspondence related to this article should be addressed to Todorka Kineva, 1700 Sofia, Student Town, University of National and World Economy, Office 2106. Email: t.kineva@unwe.bg

\section{Бележки за автора}

Тодорка Кинева (D) https://orcid.org/0000-0002-2108-048X

Авторът няма конфликт на интереси.

Кореспонденцията, свързана с тази статия, да бъде адресирана до Тодорка Кинева, София 1700, Студентски град, Университет за национално и световно стопанство, кабинет 2106. Email: t.kineva@unwe.bg 


\begin{abstract}
The main purpose of the article is to present some of the problems and challenges modern Bulgarian families with children are facing, revealed empirically, and to make suggestions for their regulation and overcoming. To achieve the goal, answers to the following questions are being sought: what changes have occurred in modern Bulgarian families over the previous three decades, what challenges lie ahead of the families, how do they affect children, and how to be regulated and overcome?
\end{abstract}

Keywords: challenges, family, parents, children

\title{
Резюме
}

Основната цел на статията е да представи някои от проблемите и предизвикателствата пред съвременните български семейства с деца, разкрити по емпиричен път и да направи предложения за тяхното регулиране и преодоляване. За постигане на целта се търсят отговори на следните въпроси: какви промени настъпват в съвременните български семейства през последните три десетилетия, какви предизвикателства стоят пред тях, как те въздействат върху децата и по какъв начин да бъдат регулирани и преодолявани?

Ключови думи: предизвикателства, семейство, родители, деца

\author{
ARTICLE INFO: \\ Original Article \\ Received: 18, 06.2020 \\ Revised: 27, 06.2021 \\ Accepted: 14, 07.2021
}




\section{Проблеми и предизвикателства пред съвременното}

\section{българско семейство с деца}

\section{Въведение}

Новата политическа, икономическа и социална среда от 90-те години на XX в. насам предизвиква интензивна промяна в модела и функциите на българското семейство. Социално-икономическите проблеми и житейски трудности, които съпътстват българите през последните три десетилетия пряко въздействат върху тяхното репродуктивно, брачно и семейно поведение. Това е основен извод от редица статистически, демографски и социологически изследвания, проведени у нас в края на XX и началото на XXI век. Официалните статистически данни свидетелстват, че трансформацията се осъществява в посока на намаляване. От една страна това е намаляване на числеността на семействата, от друга, на пълните нуклеарни семейства, от трета, на брачните семейства, от четвърта, на броя на членовете в семейството, поради ниска или отложена раждаемост и пр.

Новата либерална идеология спомага за ценностното преориентиране на българите по отношение на формите на семеен живот. През последните десетилетия се затвърждава и разпространява все повече кохабилитацията (консенсуален съюз, безбрачно съжителство, съжителство на семейни начала без сключен брак), за сметка на по-малкото сключени бракове. Тенденцията към нарастване на двойките, съжителстващи си без брак е характерна не само за България, но и за редица европейски страни. Тя е следствие от променящите се ценности и възгледи (либерални) на хората по отношение на начина на създаване на семейство, вкл. раждането и отглеждането на деца. През последните две десетилетия все по-често се акцентира върху ценности като толерантност към различните и свобода на индивида, а това от своя страна подхранва практиките на безбрачието, на еднополовите бракове, на семейства без деца и пр.

Основната цел на статията е да представи някои от проблемите и предизвикателствата пред съвременното българско семейство с деца и по емпиричен път да се разкрият техните въздействия върху живота на децата в тях.

За постигане на целта е даден отговор на следните въпроси:

1. Какви промени настьпват в българското семейство през последните три десетилетия? 
2. Кои са предизвикателствата пред съвременните семейства и как те оказват влияние върху живота на децата в тях.

3. Какво следва да се прави за тяхното преодоляване?

\section{Метод}

Статията е разработена на базата на вторичен анализ на данни от авторско ЕСИ на тема „Жизненият свят на българката днес”, проведено в периода 13.01.-06.09.2020 г. сред 264 души - 117 мъже и 147 жени, на възраст над 18 години и на данни от качествено изследване (дълбочинни интервюта с експерти) на тема „Демографски и семейни рискове”, осъществено през 2020 г. по проект „Икономически, геополитически и социални рискове в развитието на съвременна България”, финансиран от Фонд научни изследвания към Министерство на образованието и науката в рамките на Конкурс за финансиране на фундаментални научни изследвания - 2019 г. Вторичният анализ на данните от емпиричните изследвания са валидни само за изследваната съвкупност и не могат да се генерализират. Въпреки непредставителния си характер, те разкриват някои от основните проблеми и предизвикателства пред съвременните семейства и техните деца и очертават насоки за преодоляване на рисковия характер на някои от тях.

\section{Резултати и дискусия}

\section{Какви промени настъпват в българското семейство през последните три} десетилетия?

От направения вторичен анализ на данните от проведените дълбочинни интервюта с експерти може да се направи категоричния извод, че политическите, икономическите и социалните промени в българското общество предизвикват трансформации във функциите на семейството. Днешното семейство, според мнението на експертите, „се лишава/занижава/ от някои свои задължителни функции или придобива нови форми на тяхното осъществяване”. Акцентьт в анализа е поставен върху икономическата, репродуктивната, емоционалната и социализиращата функция.

По отношение на икономическата функция на семейството, експертите насочват вниманието към промяната в осигуряване издръжката на живот на семейството и неговия икономическия статус. Тук ясно се откроява прехода от осигуряване на трудови доходи единствено от наемен труд и трансферни плащания към трудови доходи от наемен труд, свободни професии, собствен бизнес и нетрудови доходи - от рента, наеми, дивиденти от акции, трансферни плащания, инвестиционни дялове, ценни 
книжа, от неформалната икономика и пр. По думите на един от експертите, разпадът на съставните домакинства на отделни семейства, както и преразпределянето на икономическите функции на общото домакинство към всяко от тях, предопределя тяхната самостоятелност днес. Следва да се отбележи и промененото участие на съпрузите/партньорите в приходната и в разходната част на семейния бюджет. Както казва един от експертите „осигуряването на доходите не е отговорност само на единия от партньорите". Безспорен факт е, че в голяма част от българските семейства и двамата съпрузи/партньори работят и осигуряват издръжката на семейството, както и че има семейства, в които работи само единият, поради различни причини безработица, обучение, здравословни проблеми, домакинстване и пр. Днес не са рядкост и семейства, в които жената получава по-висок доход от мъжа, както и обратното - семейства с патриархални възгледи и нагласи, според които мъжът изцяло издържа семейството. Във връзка с последното, експерт, базирайки се на своя дългогодишен професионален опит споделя следното: „много млади хора, в различни изследвания, отговарят, че не желаят да се женят, защото съвременните девойки търсели хора с повече пари, да живеят на тяхна издръжка”.

Според експертите, основен фактор за промяната на икономическия статус и функции на българското семейство е семейният бизнес. От една страна, възникването на семейния бизнес в условията на демокрация помага за възраждане на семейството като икономическа институция. От друга, механизмите на пазарното стопанство предизвикват промени в структурата на семейството, в ролите и отговорностите на съпрузите/партньорите и във взаимоотношенията между всички негови членове.

Промени се установяват и по отношение на репродуктивната функция на семейството. Основната промяна е по посока на все по-ниска раждаемост. Формира се репродуктивна реализация на 1 или най-много 2 деца в семейството, както и на семейства без деца, поради различни причини - здравословни, икономически, социални и пр. Безспорен факт е, че „негативната тенденция в промените на раждаемостта се оформя вече като рискова". По мнение на експертите, причините за ниската раждаемост в България се дължат на намаляващите родилни контингенти и на отложената раждаемост. Тези процеси са особено рискови, тъй като, по думите на един от експертите, това „води до късно създаване, или не създаване на семейства, а оттам и намаление в реализацията на репродуктивните възможности - ниски коефициенти на плодовитост". 
Друг момент, който изследването откроява е промяна в ценностната система и репродуктивното поведение на българите. Все по-често хората предпочитат да имат помалко деца, но да ги отглеждат качествено - резултат от увеличаващите се обществени потребности, очаквания и изисквания. По думите на един от експертите „потребности от деца““ в съвременното общество не са намалели, но техният размер се компенсира с увеличаване „качеството на детето“, т. е. броят на децата е по-малък поради повисокото качество”. Част от експертите твърдят, че основното ограничение за осъществяване на репродуктивните намерения на българските семейства е с икономически характер. Към него следва да се добавят еманципацията и многостранността на промените в социалния статус на жените, които увеличават интереса им към извънсемейните дейности - допълнителна работа, свободно време, грижи за себе си, делови срещи, публични изяви и др. Върху репродуктивното поведение и реализация на съвременните жени все по-често влияние оказват още продължителното образование, придобиването на по-голяма икономическа самостоятелност, постигането на по-висока професионална кариера и социален престиж, породените от идейни съображения джендър проповеди и принудително привнесени елементи на т.нар. женска еманципация и пр. Всичко това изменя ценностното отношение към семейството и към раждането и отглеждането на по-голям брой деца.

Някои от експертите насочват вниманието върху високите равнища на извънбрачна раждаемост в България, но е коректно да се посочи, че голяма част от извънбрачно родените деца са на родители, живеещи на семейни начала и практически тези деца живеят в реална семейна среда, а не в институции. Текущата демографска статистика разкрива, че с всяка изминала година относителният дял на извънбрачните раждания се повишава, като от 2006 г. насам извънбрачните раждания превишават брачните. Ако относителният дял през 2000 г. на извънбрачно родените деца е около 38,4\% от всички живородени, то през 2020 г. са 59,7\% (НСИ, Демографска и социална статистика). Основната причина за тази тенденция е изменената структура на населението по юридическо семейно положение, където намалява делът на омъжените/женени за сметка на лицата, несключили брак. По мнение на един от експертите „брачното семейство вече не е тази единица, която е напълно решаваща за живота и възпроизводството на хората, тъй като повече от половината от децата се раждат извън брака". Един от ефектите от разпространението на съжителствата без 
брак е разделянето на брака от родителството - раждането на първо дете предхожда сключването на първи брак. Официалните статистически данни разкриват, че през 2019 г. средната възраст на жените при раждане на първо дете е 27,3 г., а при сключване на първи брак е съответно 29,1 г. (НСИ, 2020, с. 38). В началото на XXI в. бракът и родителството нямат силно причинно-следствен характер, какъвто е характерен за миналото, защото съвременният обществен модел, ценности и отношения позволяват съществуването им отделно и независимо едно от друго.

Очертава се един потенциален риск, който има морален характер. Свързан е с раждането на дете без съпруг, детето да не познава биологичния си родител, сурогатното майчинство, самотното родителство, еднополовите семейства и др. Това са различни начини за справяне с проблема на бездетието при някои семейства, но същевременно предизвикват морални проблеми, които засягат както отглеждането, възпитанието и социализацията на детето, така и отношенията вътре в семейството и извън него.

Емоционалната функция на семейството се определя от експертите като изключително важна за семейните отношения, вкл. за съхраняването на семейството. Промяната тук, според двама от експертите, се осъществява най-вече по посока на емоционалните и сексуалните отношения между партньорите, както и на взаимовръзките родители-деца и братя-сестри. В това отношение един от експертите е категоричен, че „емоционалните връзки в семейството са нарушени, обезценени и духовно снизени”, както и че „създаването и заздравяването на емоционалните връзки между членовете на семейства е съществена обществена потребност, която неправителствените организации и държавните институции следва да развиват в областта на семейното планиране и сексуално възпитание.”

Едновременно с това вниманието се съсредоточава и върху намаляване „влиянието” на възрастното поколение върху младото семейство. Както се изразява един от експертите „Старите поколения имат влияние върху раждаемостта и семейството - стремят се да го задържат, дори ако двойката не се разбира; държат да имат не едно, а две деца (двудетен модел и двудетно семейство)...”, докато в съвременните условия това въздействие намалява своя интензитет. Това може да се обясни с процесите на миграция и емиграция, либерални възгледи, желание за самостоятелност на младите и за ненамеса в техните семейни отношения и пр. 
Като цяло мнението на експертите относно емоционалната функция е оскъдно. Необходимо е специализирано проучване, което детайлно да установи състоянието и промените, например при: оказване на взаимна подкрепа и закрила между партньорите, между родителите и децата, между родителите и прародителите (без и с участието на децата); начина на изграждане самоидентификацията на децата със семейството и фамилията, с роднинския и особено с приятелски кръг на родителите, необходим в конкретна и особено нова социална среда (например в друго населено място, в чужбина); общуване в семейството - в проявите на интимност, близост, приятелство, на духовно и физическо общуване на изграждането на взаимно доверие, уважение и взаимопомощ; начина на формиране на емоционалната и на социалната интелигентност на родителите и децата в семействата и пр.

По отношение на социализиращата функция на семейството се открояват две направления - промени в начина на отглеждане и възпитание на децата и в тяхното образование. Изследването позволява да се установи, че моделът и стилът на обучение и възпитание на децата търпи изменения най-вече поради непрекъснати промени в образователната система и упражнявания натиск от управляващите страната (икономически, социален и културален). Икономическата несигурност и непрекъснато растящите изисквания към родителството, свързана с въвеждането на либерални стилове на обучение и възпитание на децата, зараждащото се отчуждение, насилие и агресивност в и извън семейството са фактори, които експертите посочват, че оказват въздействия върху степените на социализация на съвременните деца. Все по-често се чува въпросът „Как да възпитаваме децата си правилно, за да са здрави физически и психически?”. Съвременните родители се оказват в ситуация на непрекъснато търсене на баланс - между грижата и пълноценното общуване, контрола и дисциплината, отговорността и поведението и както казва един от експертите „наблюдаваме, че част от родителите вече не знаят в какво да възпитават децата си, защото са объркани и не могат да преценят".

Едновременно с това, работещите родители са изправени пред проблема съчетаване на семейство и работа, като част от тях нямат възможност да отделят достатъчно време на своите децата, което създава семейни проблеми. Възпитателният стил на родителите днес се сблъсква с ежедневните предизвикателства у дома, в детската градина, в училище, на улицата, в приятелския кръг, в интернет пространството и пр. 
Експертите идентифицират и проблема с децата, отглеждани от прародителите (баба и дядо). Такива са случаите, при които родителите се намират в друго населено място или в чужбина, поради редица причини, най-често икономически. Споделените от експертите мнения разкриват, че отсъствието на родителите се отразява както положително, така и негативно върху възпитанието и социализацията на техните деца. Положителното въздействие се отразява по различни начини. Една част от тези деца приемат с разбиране тяхното отсъствие, доволни са от подобрения си стандарт на живот, в резултат на паричните средства, които им изпращат; други деца продължават мотивирано обучението си в България, като очакват търпеливо заврьщането на родителите си или заминаването си при тях; трети живеят с надежда, че могат да продължат образованието си при тях в чужбина; четвърти, не желаят да заминават, тъй като ще загубят свободата си и пр. Негативното отражение върху децата се изразява най-малко в следното: една част от тях се отчуждават напълно от родителите си; друга - частично загубват тясната връзка помежду си; трета част загубват интерес към обучението си, напускат училище, изостават в социализацията си; четвърта част са склонни да приемат живота на наркомани, проститутки, крадци, престьпници и пр.

Експертите са единодушни, че е необходим нов модел на образование във всички степени и видове учебни заведения. Те не подкрепят „сегашното прехласване спрямо дистанционното обучение по време на пандемията", поради причини като отсъствие на личен контакт с преподавателите, не добро и пълноценно усвояване на преподавания учебен материал, липса на равен достъп до дигитално обучение (не всички имат компютър и/или интернет); тестовият контрол не развива дискусионните способности на децата, отчуждение между децата, между тях и техните учители и пр.

\section{Какви са предизвикателствата пред съвременното семейство и как те въздействат върху децата?}

За отговора на този въпрос се използват данни от авторско количествено ЕСИ на тема „Жизненият свят на българката днес”, проведено в периода 13.01.-06.09.2020 г. сред 264 души - 117 мъже и 147 жени, на възраст над 18 години. Вторичният анализ на резултатите от изследването за жизнения свят на българката разкрива наличие на редица предизвикателства пред българските семейства. Като първо и основно предизвикателство респондентите посочват финансово-материалните проблеми, които според тях се явяват реална предпоставка за изпадане на семейството в риск от бедност, а това застрашава благосъстоянието на детето/децата в него. Финансово-материалните 
проблеми са породени преди всичко от ниските доходи, които получават жените и мъжете от изследваната съвкупност, от перманентната безработица, която ги съпътства и която поражда икономическа несигурност и нестабилност на семейството, ниският стандарт на живот и липсата на самостоятелно жилище ги демотивира да раждат деца и пр. Не са редки случаите, при които финансовите проблеми предизвикат нарушаване на добрия тон и разбирателство между съпрузите/партньорите, между тях и децата, провокират сериозни конфликти и разрушават устойчивостта и целостта на семейството. Поради бедност в семейството част от децата не успяват да се включат в онлайн обучението (по време на извънредната епидемична обстановка), защото нямат необходимата техника и интернет връзка. В резултат на това имат дефицити, изостават от връстниците си, пропускат възможности за придобиване на дигитални умения, чувстват се непълноценни и пр.

Като второ предизвикателство респондентите посочват осигуряването на необходими и достатъчни условия за качественото и пълноценно отглеждане, възпитание и социализация на децата. Това изисква от родителите създаване и поддържане на подходящи жилищни и битови условия за живеене, полагане на грижи за запазване на физическото и психическото здраве на децата, за тяхното възпитание, образование и социализиране (в т.ч. и с участието на прародителите и институциите). Отсъствието на част от тези условия почти винаги предизвиква тревожност, нервност и конфликти в семейството. Това предизвикателство е особено актуално в условия на Ковид-19. Затварянето на детски и учебни заведения и съпьтстващата ги пълна дигитализация на образователния процес създава предпоставки за задълбочаване на редица рискове пред децата - невключване в онлайн обучението; повишаване на риска от отпадане на ученици; по-ниско качество на усвояваните знания и умения, неудовлетвореност от учебния процес; липса на концентрация и интерес към учебния материал; отчужденост от учители, съученици, приятели; продължително застояване пред електронните устройства; липса на физическа активност, и пр.

Тук следва да се отбележи и влиянието на съвременната техника и технологии върху живота на децата. Все по-малки деца играят на електронни игри, сърфират в интернет, стават зависими от смартфоните, отчуждават се от връстниците си, от четенето на книги на хартиен носител, загубват интерес към учебния материал, не се стараят да запаметяват, да натрупват знания, а само как да намират нужната им информация в интернет, високата степен на радиоактивност и вредни влияния 
предизвикват редица заболявания и пр. Същевременно застояването на децата пред смартфорна, компютьра и телевизора води до понижена физическа активност и повишава риска от затльстяване и болести, предизвикани от наднорменото тегло (UNICEF, 2017, p. 41). Според експерти медици, през последните години се регистрира увеличаване на зрителните нарушения и очните заболявания при децата, вкл. поява на т.нар. „дигитална очна умора“. Налице е пристрастяване към електронните устройства, идентифицират се нови онлайн рискове за децата - свързани със съдържанието в интернет (неподходящо за тяхната възраст), с контактите (с непознати, които може да ги уязвят и наранят) и с поведението им (UNICEF, 2017, р. 72).

На трето място респондентите посочват отсъствието на здрава емоционална връзка и сплотеност в семейството, предизвикана от недостатъчна взаимопомощ и подкрепа между съпрузите, липса на съпричастност при изпълняване на основни семейни ангажименти, професионален стрес и свръхангажираност, ненамиране на свободно време за семейни развлечения, за отдих и общуване с децата, с близки, роднини, приятели и пр.

Четвърто предизвикателство пред семействата е как работещите съпрузи/партньори да съвместят семейния и професионалния си живот по начин, който да съхрани устойчивостта на семейството. Тази проблематика е обект на сериозни изследвания от различни специалисти не само у нас (Ковачева, 2010; Йорданова, 2020; Кинева, 2020; Gragnano et al., 2020; Holmes et al., 2020) Младите родители са изправени пред сериозни трудности в търсене на необходимия баланс, особено в условия на дефицити - институционални и социални, на обществени трансформации, конфликти и кризи (Stoyanova, 2014) и пр. Ако се актуализират и конкретизират примерите от реалната действителност, то пандемията Ковид-19 поставя работещите родители и особено работещите майки в тежка ситуация на съвместяване на работата от вкъщи (виртуален труд) с отглеждането и обучението на децата (в предучилищна и училищна възраст), принуждава част от тях да ползват неплатени отпуски, други да напуснат работата си, ако тя не позволява дистанционна форма.

\section{Какво следва да се прави за преодоляване на проблемите и предизвикателствата?}

Неоспорим факт е, че всяка промяна при съвременните семейства предизвиква проблеми, нерешените или трудно решими проблеми прерастват в предизвикателства, а предизвикателствата крият рискове, които съдържат както опасности, така и възможности за всяко семейство. За регулирането на проблемите и 
предизвикателствата са необходими действащи ефективни държавни политики, регулиращи демографските процеси, семейното планиране, социални политики, подпомагащи младите семейства при: осигуряване на семеен дом; семейни добавки, покриващи разходите по отглеждането, опазване на здравето и образованието на децата до пълнолетие; за закрила на майките и майчинството; за запазване на работните места на майките след заврьщане от отпуската по майчинство; специални стимули за майките да раждат повече от 1 дете; мотивиране на майките да повишават квалификацията си и да правят професионална кариера и пр. Необходими са нови социални мерки за регулация, отговарящи на възникналите потребности на съвременните семейства. Отговорностите по тяхното създаване и реализация носи както държавата, така и бизнеса, защото основната цел е да се запази семейството като градивна и устойчива единица в обществото, за да има повече здрави и образовани деца, за да я има България.

\section{Заключение}

Настоящият анализ установява наличие на значими трансформации във функциите на съвременното българско семейство. Променят се не само нагласите за създаване на семейство, но и представата за неговите функции - икономическа, репродуктивна, социализираща и емоционална. Основни фактори за това са промените в икономическата, социалната, демографската и културалната сфера, а като кумулативни фактори се открояват еманципацията на жените (променяща не само вътрешносемейните отношения и поведение, но и икономическия статус на семейството), самостоятелност на семейството, вътрешносемейните отношения и пр.

Съвременното българско семейство е изправено пред редица предизвикателства, касаещи неговото запазване, функциониране и развитие. Изследването позволява да се направи извода, че проблемите и предизвикателствата пред съвременните български семейства и техните деца не могат да бъдат решени сами по себе си, а чрез регулативни мерки от държавата и бизнеса.

\section{Използвана литература}

Gragnano, A., Simbula, S., \& Miglioretti, M. (2020). Work-life balance: Weighing the importance of work-family and work-health balance. International Journal of Environmental Research and Public Health, 17(3), 907. https://doi.org/10.3390/ijerph17030907. 
Holmes, E., Thomas, C., Petts, R., \& Hill, E. (2020). The work-family interface. In W. K. Halford, \& van der Vijver, F. (Eds), Cross-Cultural Family Research and Practice (pp.323-354). Academic Press.

https://doi.org/10.1016/B978-0-12-815493-9.00010-7

Kineva, T. (2020). Rolevite konflikti na savremennata balgarska zhena: mezhdu semeystvoto $i$ karierata. [Role conflicts of present-day Bulgarian woman: between the Family and the Career]. UNWE Publishing House.

Kovacheva, S. (2010). Balans mezhdu rabota i semeystvo. Mladite raboteshti roditeli mezhdu vazmozhnostite i ogranicheniyata. [Balancing between work and family. Young working parents between possibilities and limitations]. East-West Publishing House.

National Statistical Institute. (2020). Demografski protsesi prez 2019 godina [Demographic processes in 2019]. NSI.

https://www.nsi.bg/sites/default/files/files/publications/DMGR2019.pdf

National Statistical Institute. (2021). Demografska i sotsialna statistika [Demographic and social statistics].NSI. Retrieved July 20, 2021 from https://infostat.nsi.bg/infostat/pages/reports/result.jsf?X_2=890

Stoyanova, M. (2014). Konfliktite prez prizmata na sotsiologiyata. [Conflicts through the prism of sociology]. (2nd ed). UNWE Publishing Hause.

UNICEF. (2017). The state of the World's Children 2017 - Children in a Digital World. Retrieved July 05, 2021 from https://www.unicef.org/bulgaria/en/reports/state-worlds$\underline{\text { children-2017-children-digital-world }}$

UNICEF. (2018). Situation analysis of children and women in Bulgaria, 2017. Retrieved May 2021 from https://www.unicef.org/bulgaria/media/2821/file/BGR-situation-analysischildren-women-bulgaria.pdf.pdf

Yordanova, G. (2020). Virtualniyat ofis: nova vazmozhnost za balansa rabota-semeystvo $v$ IKT sektora v Bulgaria. [The virtual office: a new opportunity for work-family balance in the ICT Sector in Bulgaria]. Academic Publishing House „Prof. M. Drinov““. 